\title{
The role of eosinophils in sepsis and acute respiratory distress syndrome: a scoping review
}

\section{Le rôle des éosinophiles dans le sepsis et le syndrome de détresse respiratoire aiguë : une revue exploratoire}

\author{
Zainab Al Duhailib, MBBS, EDIC (D) - Malik Farooqi, MBBS · Joshua Piticaru, MD • \\ Waleed Alhazzani, MBBS, FRCPC, MSc · Parameswaran Nair, MD, PhD, FRCP, \\ FRCPC
}

Received: 23 June 2020/Revised: 24 November 2020/Accepted: 26 November 2020/Published online: 25 January 2021

(C) Canadian Anesthesiologists' Society 2021

\begin{abstract}
Purpose Septic shock and acute respiratory distress syndrome (ARDS) are characterized by a dysregulated immune host response that may respond to steroid therapy. Eosinophils contribute to type 2 inflammation that often responds to steroid therapy; their role in immune dysregulation and outcomes in sepsis and ARDS is unclear. Source A systematic search of Cochrane Library, MEDLINE, and EMBASE was performed from inception to 9 September 2020. The search comprised the following terms: eosinophils, sepsis, septic shock, and ARDS. Two reviewers independently screened abstracts and texts and extracted data on disease severity and clinical outcomes. Principal findings Thirty-nine studies were identified: 30 evaluated serum eosinophil count in sepsis, one evaluated
\end{abstract}

Supplementary Information The online version of this article (https://doi.org/10.1007/s12630-021-01920-8) contains supplementary material, which is available to authorized users.

Zainab Al Duhailib and Malik Farooqi: Contributed equally to the manuscript.

Z. Al Duhailib, MBBS, EDIC ( $₫)$

Department of Health Research Methods, Evidence and Impact,

McMaster University, 1280 Main Street West, Hamilton, ON

L8S 4K1, Canada

e-mail: alduhaiz@mcmaster.ca

Department of Critical Care Medicine, King Faisal Specialist

Hospital and Research Centre, Riyadh, Saudi Arabia

Department of Medicine, Division of Critical Care, McMaster

University, Hamilton, ON, Canada

M. Farooqi, MBBS · P. Nair, MD, PhD, FRCP, FRCPC eosinophil activity in sepsis, three assessed bronchoalveolar lavage (BAL) eosinophil count in ARDS, four assessed eosinophil activity in ARDS, and one assessed peripheral eosinophil count in ARDS. Eleven studies showed an association between eosinopenia and sepsis, and eight studies found persistent eosinopenia at $>$ $48 \mathrm{hr}$ of intensive care unit admission to predict mortality and readmission in septic patients. Three studies found $B A L$ eosinophil count to be low in ARDS, although one found that levels rose in late-phase ARDS. Three studies found eosinophil activity markers in BAL to be high in $A R D S$ and correlate with ARDS severity.

Conclusion Persistent peripheral eosinopenia is a marker of bacterial sepsis and is independently associated with poor outcomes. Bronchoalveolar lavage eosinophil counts are low in early-phase ARDS, but increase in late-phase ARDS, while elevated markers of eosinophil activity correlate with ARDS severity. Further studies understanding the mechanisms leading to eosinopenia in sepsis and increased eosinophil activity in ARDS are needed.

Department of Medicine, Division of Respirology, St Joseph's Healthcare and McMaster University, Hamilton, ON, Canada

J. Piticaru, MD

Department of Medicine, Division of Critical Care, McMaster University, Hamilton, ON, Canada

W. Alhazzani, MBBS, FRCPC, MSc

Department of Health Research Methods, Evidence and Impact, McMaster University, 1280 Main Street West, Hamilton, ON L8S 4K1, Canada

Department of Medicine, Division of Critical Care, McMaster University, Hamilton, ON, Canada 


\section{Résumé}

Objectif Le choc septique et le syndrome de détresse respiratoire aiguë (SDRA, ARDS en anglais) se caractérisent par une réponse immunitaire dérégulée chez l'hôte qui pourrait répondre à une corticothérapie. Les éosinophiles contribuent à l'inflammation de type 2, laquelle répond souvent à la corticothérapie; leur rôle dans la dérégulation immunitaire et les devenirs en cas de sepsis et de SDRA n'est pas clair.

Source Une recherche systématique dans les bases de données Cochrane Library, MEDLINE et EMBASE a été réalisée de leur création au 9 septembre 2020. La recherche comprenait les termes suivants : éosinophiles, sepsis, choc septique et SDRA. Deux réviseurs ont examiné de manière indépendante les résumés et textes et ont extrait les données décrivant la gravité de la maladie et les devenirs cliniques.

Constatations principales Trente-neuf études ont été identifiées : 30 études portaient sur le décompte d'éosinophiles sériques lors de sepsis, une étude examinait l'activité des éosinophiles dans un contexte de sepsis, trois ont évalué le décompte d'éosinophiles par lavage bronchoalvéolaire (LBA) dans les cas de SDRA, quatre ont examiné l'activité des éosinophiles dans le SDRA, et une a évalué le décompte d'éosinophiles périphériques dans les cas de SDRA. Onze études ont montré une association entre l'éosinopénie et le sepsis, et huit études ont remarqué qu'une éosinopédie persistante pour plus de 48 heures après l'admission à l'unité de soins intensifs était un prédicteur de mortalité et de réadmission chez les patients septiques. Trois études ont révelé que le nombre d'éosinophiles dans un LBA était faible en cas de SDRA, bien qu'une étude ait constaté que les taux augmentaient dans les SDRA de phase tardive. Trois études ont révélé que les marqueurs d'activité éosinophilique dans les LBA étaient élevés dans les cas de SDRA et étaient corrélés à la gravité du SDRA.

Conclusion L'éosinopénie périphérique persistante est un marqueur de sepsis bactérien et est indépendamment associée à de mauvais pronostics. Les décomptes d'éosinophiles dans les lavages bronchoalvéolaires sont bas dans les cas de SDRA en phase précoce, mais augmentent dans le SDRA en phase tardive, alors que des marqueurs élevés d'activité éosinophilique sont corrélés à la sévérité du SDRA. D'autres études visant à comprendre les mécanismes menant à l'éosinopénie dans le sepsis et à l'augmentation de l'activité éosinophilique dans le SDRA sont nécessaires.

Keywords eosinophils $\cdot$ eosinopenia $\cdot$ sepsis · acute respiratory distress syndrome (ARDS)
Septic shock remains a leading cause of death worldwide, with a mortality rate greater than $40 \%$ despite substantial efforts to improve early identification and management. ${ }^{1}$ Acute respiratory distress syndrome (ARDS) is a common complication of septic shock and is associated with an even higher mortality rate of over $60 \% .^{2}$ Both septic shock and ARDS are characterized by a severe inflammatory state resulting from a dysregulated immune host response. Guidelines have supported the use of corticosteroids in these conditions to mitigate these complex inflammatory processes, although the recommendations have been conditional because of inconclusive evidence. ${ }^{3-5}$

Steroids are generally effective in conditions associated with eosinophils; raised eosinophils in blood or sputum are markers of steroid responsiveness in a number of airway diseases such as asthma, ${ }^{6}$ chronic cough, ${ }^{7}$ and chronic obstructive pulmonary disease (COPD). ${ }^{8}$ It is not known if eosinophils in sepsis or ARDS have similar theragnostic value. The classical model of immune dysregulation in sepsis describes activation of the innate immune system in response to antigens such as lipopolysaccharides in gram negative bacteria. This results in the release of cytokines such as interferon- $\gamma$ and interleukin-12 (IL-12), which activate adaptive immunity through $\mathrm{T}$ helper $1\left(\mathrm{~T}_{\mathrm{H}} 1\right)$ cells, ${ }^{9}$ characterized typically by high levels of IL-6, IL-8, IL-1, and tumour necrosis factor- $\alpha$ (TNF $\alpha$ ). This "type- 1 inflammation" is also involved in the development of $\operatorname{ARDS}^{10}$ and precipitates a pro-inflammatory cascade characterized by intense phagocyte activity and host tissue destruction. ${ }^{11}$ In contrast, type 2 inflammation is characterized by the activation of $\mathrm{T}_{\mathrm{H}} 2$ cells, which results in eosinophil activation in response to extracellular organisms that cannot be phagocytosed, such as helminths. Type 2 inflammation initiates tissue repair through myofibroblast activation and angiogenesis, and is hypothesized to balance the pro-inflammatory type 1 responses in sepsis. ${ }^{12}$ Imbalance between type 1 and type 2 responses leads to immune disequilibrium and may lead to poor outcomes seen in both sepsis and ARDS..$^{10,11}$ As eosinophils are also activated by type 2 inflammation, their absence (eosinopenia) may indicate immune imbalance. Alternatively, eosinopenia may be a consequence of eosinophil consumption, and eosinophils may contribute to the dysregulated host response in infection and ARDS. Eosinophil recruitment into inflamed tissue can cause tissue damage by generating oxidative stress through eosinophil peroxidase (EPO) and by cytotoxicity through the release of granule proteins such as eosinophil cationic protein (ECP) and extracellular trap cell death. ${ }^{13}$ Eosinophil trafficking into lung tissue in ARDS may contribute to alveolar damage, capillary leak, interstitial edema, and inflammation through these mechanisms. ${ }^{14,15}$ 
Elevated levels of ECP may better reflect eosinophil activation than eosinophil count in these circumstances.

In this scoping review, we summarize and map the associations between peripheral eosinophil levels and peripheral eosinophil activity and clinical outcomes in patients with sepsis, as well as describe bronchoalveolar lavage eosinophil (BAL) levels and activity in states of immune dysregulation using the ARDS model. Further understanding of potential pathways leading to immune imbalance in sepsis and ARDS are needed and a review of this evidence may help identify knowledge gaps for future research.

\section{Methods}

Information source and search strategy

A certified librarian conducted a systematic search of Cochrane Library, MEDLINE®, and EMBASE® electronic databases, using the OvidSP search interface, from inception to September 2020. To identify all relevant studies, a search strategy using combinations of controlled vocabulary (subject headings) and keywords was adopted. This comprised the following search terms: eosinophils, sepsis, septic shock, and ARDS. The review had no restrictions on the study designs. We have attached our full literature search strategy as an Electronic Supplementary Material eTable (ESM). The search strategy was peerreviewed as per the Peer Review of Electronic Search Strategies (PRESS) 2015 guideline. ${ }^{16}$ The PRESS checklist includes six domains that assess the appropriate translation of the research question and use of search concepts, headings and subheadings, filters and limits, spelling and syntax, proximity operators, and text word searching with the use of appropriate synonyms and abbreviations. The protocol was registered in the research registry website (unique identifying number: reviewregistry982). ${ }^{17}$

\section{Selection criteria}

Only studies with adult human participants (age $\geq 18 \mathrm{yr}$ ) and published in English were included. Studies conducted in the pediatric population and animal studies were excluded, as were case reports and review articles. Any study that assessed BAL, peripheral blood eosinophil counts or activity in sepsis or ARDS, and clinical outcomes (disease associations and/or severity) were eligible. Two reviewers (ZD and JP) screened titles and abstracts to be included for full review. The reviewers further evaluated the full-text for eligibility criteria, and disagreements were resolved by consensus. Data abstraction was done by two reviewers (ZD and JP) using a standardized data abstraction form. Descriptive information on study design, key inclusion criteria, sample size, eosinophil level/marker, and clinical outcomes (mortality, hospital readmission, ARDS severity) were abstracted.

Methodologic quality assessment

We used the Newcastle-Ottawa regulations coding manual and assessment scale (NOS) for case-control and cohort studies to assess the quality and risk of bias of each study. ${ }^{18}$ It uses a "star system", which involves assessing the studies for three main domains including: selection of the study groups; comparability of the study groups; and ascertainment of either the exposure or outcome of interest for case-control or cohort studies, respectively. Two reviewers (ZD and $\mathrm{MF}$ ) independently assessed risk of bias in all eligible studies and disagreements were resolved by discussion and consensus.

\section{Results}

The search strategy yielded 917 articles, with 39 studies remaining after removing duplicates and irrelevant articles (Figure). Thirty studies evaluated peripheral eosinophil counts in sepsis, ${ }^{19-48}$ one study evaluated peripheral eosinophil activity in sepsis, ${ }^{49}$ three studies assessed BAL eosinophil count in ARDS, ${ }^{50-52}$ four studies assessed peripheral and BAL eosinophil activity in ARDS, ${ }^{14,15,53,54}$ and one study evaluated peripheral eosinophil counts in ARDS. ${ }^{55}$ More than half of the studies were deemed to be of poor overall quality using the NOS (Table).

Eosinophils in sepsis and septic shock

Many studies have evaluated the association between peripheral blood eosinophil counts and sepsis with inconsistent results. The 30 studies that evaluated this question had significant heterogeneity with respect to their study design, patient population, methodology, and outcomes assessed.

\section{Eosinophil levels in septic vs non-septic patients}

Five studies showed that eosinopenia (eosinophil count $<$ $0.05 \times 10^{9} \cdot \mathrm{L}^{-1}$ ) discriminated infected patients (those with sepsis, severe sepsis, and septic shock) from non-infected patients (systemic inflammatory response syndrome [SIRS]) only as per 1992 American College of Chest Physicians/Society of Critical Care Medicine Consensus Definition, ${ }^{56}$ with a C-statistic range of 0.72 to 
0.89..$^{20,24,26,35,45,46}$ One study described a positive association between increasing eosinophil count and sepsis compared with non-septic trauma patients admitted to the intensive care unit (ICU). ${ }^{19}$ Five studies did not report a difference in eosinophil count between infectious and non-infectious SIRS groups. ${ }^{22,23,33-35}$ Nevertheless, these studies are limited by small sample sizes (range 66-185) and cross-sectional study designs.

\section{Eosinophil levels and clinical outcomes in septic patients}

Twelve studies described an association between persistent eosinopenia and mortality. Merino et al. showed that an eosinophil count $<0.05 \times 10^{9} \cdot \mathrm{L}^{-1}$ at $96 \mathrm{hr}$ after ICU admission had a C-statistic of 0.65 (95\% confidence interval $[\mathrm{CI}], 0.67$ to 0.73$)^{26}$ to discriminate 30 -day mortality. Of note, as per the study centre guidelines all patients were given hydrocortisone $50 \mathrm{mg}$ iv $q 6 h$. Terradas et al. used survival analysis to determine predictors of 15-day mortality in patients with bacteremia. ${ }^{28}$ They found that patients with an eosinophil count persistently below $0.0454 \times 10^{9} \cdot \mathrm{L}^{-1}$ had a hazard ratio (HR) of $4.20(95 \% \mathrm{CI}$, 2.66 to 6.62 ) for death compared with the reference group of patients with eosinophils $>0.15 \times 10^{9} \cdot \mathrm{L}^{-1}$, after adjusting for age, sex, comorbidities, steroid use, and vasopressor use. Yip et al. expanded on these findings by following 1,446 patients after ICU discharge (median [interquartile range (IQR)] follow up 26 [22-30] months and found eosinopenia on ICU discharge $(<0.01 \times$ $10^{9} \cdot \mathrm{L}^{-1}$ ) to be associated with ICU readmission (odds ratio, $2.50 ; 95 \% \mathrm{CI}, 1.38$ to $4.50 ; P=0.002$ ) and post-ICU mortality (HR, $2.65 ; 95 \% \mathrm{CI}, 1.77$ to $3.98 ; P=0.001$ ) after adjusting for baseline characteristics, cause of admission, comorbidities, and sepsis severity. ${ }^{32}$ Similarly, Mahmoud et al. found an increased ICU and hospital length of stay in patients with eosinopenia. ${ }^{44}$ Specific subgroups of patients have also been shown to do poorly with eosinopenia in the context of sepsis. Patients with cirrhosis, ${ }^{29}$ clostridium difficile infection, and COPD exacerbations all had increased mortality with sepsis-associated eosinopenia (eTable, ESM). ${ }^{30,36}$ The largest study $(n=68,648)$ to evaluate this association has been published only in abstract form. ${ }^{40}$ They found eosinopenia at $48 \mathrm{hr}$ to be significantly associated with 90-day mortality, 30-day readmission, and discharge to a care facility (ESM eTable). Overall, most evidence suggests that eosinopenia is associated with poor outcomes in sepsis.

Two studies that met inclusion criteria evaluated different clinical outcomes than mortality and readmission. Pestana et al. assessed the utility of adding peripheral eosinophilia $(>3 \%$ ) to a model using baseline cortisol levels to determine hemodynamic improvement after steroid treatment and found no added discrimination with eosinophilia. ${ }^{41}$ Laviolle et al. assessed eosinophil levels after steroid administration in septic patients and found an $88 \%$ decrease in mean eosinophil counts after steroid administration compared with placebo; however there was significant overlap between eosinophil levels in the placebo group (median [IQR] baseline eosinophil count 0 [0-90] cells $\left./ \mathrm{mm}^{3}\right)$ and the steroid group (0 [0-65] cells/ $\left.\mathrm{mm}^{3}\right) .^{25}$

\section{Eosinophil activity and clinical outcomes in septic patients}

Only one study evaluated peripheral eosinophil activity in sepsis by evaluating eosinophil CCR3 expression (eotaxin receptor, type 2 chemokine) and eosinophil CRTH2 expression (chemoattractant receptor-homologous molecule). ${ }^{49}$ They found CRTH2 and CCR3 expression on eosinophils was severely decreased in patients after the onset of shock, despite the eosinophil count being unchanged. Survivors showed a non-significant trend towards higher levels of CRTH2- or CCR3-positive eosinophils compared with non-survivors. The authors conclude that patients with prolonged "immunoparalysis" as described by reduced CRTH2 and CCR3 expression, markers of a Th2 response, are susceptible to worse outcomes as it indicates a more severe form of sepsis.

\section{Eosinophils in ARDS}

\section{Bronchoalveolar lavage eosinophil levels and ARDS}

Three studies evaluated BAL eosinophil levels in ARDS. Allen et al. described BAL eosinophilia as a differential count of $>5 \%$ and found only one out of 29 patients with ARDS to have BAL eosinophilia. ${ }^{50}$ Mean BAL eosinophil count was not described. Nakos et al. compared BAL total eosinophil count between healthy controls and different phases of ARDS. ${ }^{52}$ They found that eosinophil counts significantly increased in the late phase of ARDS, to a degree similar to studies of idiopathic pulmonary fibrosis. The mean (standard deviation) Bronchoalveolar lavage eosinophil count was $0.5(0.1)(\mathrm{x} 1,000 / \mathrm{mL})$ in healthy controls, compared with 1.8 (2.9) in the early phase of ARDS, 2.0 (2.2) in the intermediate phase, and 9 (4.2) in the late phase. Jacobs et al. described an eosinophil range of $0-5.8 \times 1,000 / \mathrm{mL}$ in ARDS patients with pneumonia. ${ }^{51}$ Willetts et al. assessed a novel monoclonal antibody immunohistochemistry stain recognizing EPO (EPX-mAb) to identify eosinophils in lung biopsy specimens of patients with acute lung injury, defined in this study as any pulmonary disease characterized by life-threatening hypoxemic respiratory failure and diffuse bilateral pulmonary infiltrates. ${ }^{54}$ They showed that EPX-mAb immunohistochemistry had a 40-fold increase in 
sensitivity compared with hemotoxylin and eosin stains in identifying eosinophils, and found lung infiltrating eosinophil numbers to be higher in acute lung injury patients that survived hospitalization compared with nonsurvivors.

\section{Eosinophil activity and ARDS}

While BAL eosinophilia is uncommon in ARDS patients, increased markers of eosinophil activity in their peripheral blood and BAL have been documented. Three studies have assessed the value of ECP, a marker of eosinophil degranulation. The first study by Hallgren et al. in $1984^{53}$ found that serum levels of ECP were higher in patients with ARDS compared with patients without ARDS, despite ARDS patients having relative peripheral eosinopenia. They hypothesized that eosinophils were being actively recruited and degranulated in ARDS lungs resulting in the low peripheral eosinophil levels and high BAL degranulation products, and suggested that eosinophils played a key role in the development of ARDS. This hypothesis was subsequently tested by Modig et al., who found that BAL ECP levels correlated with ARDS severity. ${ }^{14}$ Halgren confirmed these findings, and described ARDS patients to have a higher BAL ECP concentration compared with healthy controls (163 (85) $\mu \mathrm{g} \cdot \mathrm{L}^{-1}$ vs 19 (18) $\left.\mu \mathrm{g} \cdot \mathrm{L}^{-1} ; P<0.001\right)$ and found a significant inverse correlation $(P<0.01)$ between $\mathrm{BAL}$ ECP fluid concentrations and pulmonary oxygenation (partial pressure of arterial oxygen/fraction of inspired oxygen ratio). ${ }^{15}$

\section{Peripheral blood eosinophil count and ARDS}

Only one study evaluated the association between peripheral blood eosinophils and survival in patients with ARDS. Zhang and Wang showed that a peripheral eosinophil count below $0.05 \times 10^{9} \cdot \mathrm{L}^{-1}$ within $24 \mathrm{hr}$ of ARDS diagnosis is an independent risk factor for survival (HR, $1.5 ; 95 \%$ CI, 1.01 to $2.23 ; P=0.04$ ). ${ }^{55}$ This study was published only in abstract form and did not specify what proportion of patients had sepsis-related ARDS.

\section{Discussion}

This scoping review describes the current state of evidence surrounding the role of eosinophils in sepsis and ARDS. We found that peripheral eosinophil levels are generally lower in septic patients than in those with SIRS only. ${ }^{20,22,27,33,35,46}$ Persistent eosinopenia (defined as eosinophil level $<0.05 \times 10^{9} \cdot \mathrm{L}^{-1}$ for at least $48 \mathrm{hr}$ after ICU admission) is associated with a 2 to 4 -fold increased risk of mortality, and up to 2.5-fold increased risk of hospital readmission. Low levels of peripheral eosinophil activity are associated with poor survival in sepsis. Acute respiratory distress syndrome patients did not express BAL eosinophilia (defined as eosinophils $>5 \%$ of $\mathrm{BAL}$ differential) until the late phase of ARDS. Increased local eosinophil activity correlated with ARDS severity, whereas decreased peripheral eosinophil counts were seen in ARDS. These findings lend credence to the model of immune imbalance between type 1 and type 2 inflammation in both sepsis and ARDS.

\section{Pathomechanistic role of eosinophils in sepsis}

Although the diagnostic and prognostic significance of eosinopenia in sepsis has been highlighted in our review, the mechanism of eosinopenia in septic patients remains ambiguous. One hypothesis is that peripheral eosinopenia is a consequence of low type 2 inflammation as a result of immune imbalance. ${ }^{12}$ In an observational study of patients with septic shock, IL-5, a cytokine involved in type 2 inflammation and eosinophil maturation, was higher in survivors compared with non-survivors, despite peripheral eosinopenia. ${ }^{57}$ Murine models have shown that activated eosinophils play an important role in host defence against viral and possibly bacterial pathogens. ${ }^{58,59}$ These models have shown that type 2 responses can balance dysregulated septic pro-inflammatory responses as a result of type 1 inflammation. ${ }^{60}$ Type 2 response is associated with eosinophilia, and the absence of eosinophils may signal immune imbalance and resultant worse outcomes. Thus, it is possible that eosinophils play a role in host defence in sepsis. An alternate hypothesis is that peripheral eosinopenia is a consequence of increased tissue eosinophil recruitment and consumption. In sepsis, cytokines and chemokines (mainly $\mathrm{C} 5 \mathrm{~A}$ and fibrin fragments) have been shown to cause migration and sequestration of eosinophils at the site of infection, potentially contributing to initial peripheral eosinopenia. $^{61}$ Nevertheless, it is the persistent eosinopenia that has shown consistent associations with poor outcomes. Given the observational nature of these associations, it is difficult to establish the causality of eosinopenia in bacterial sepsis. We were unable to find studies describing the role of eosinophils in patients with viral pneumonia-induced septic shock and multiorgan failure. Further research is needed to determine if peripheral eosinopenia is a consequence of eosinophil activation and consumption, or a consequence of low type 2 immune response and immune imbalance. The single study on eosinophil activity in sepsis found low levels to be associated with worse clinical outcomes, supporting the latter hypothesis. ${ }^{49}$ Nevertheless, further research is needed 


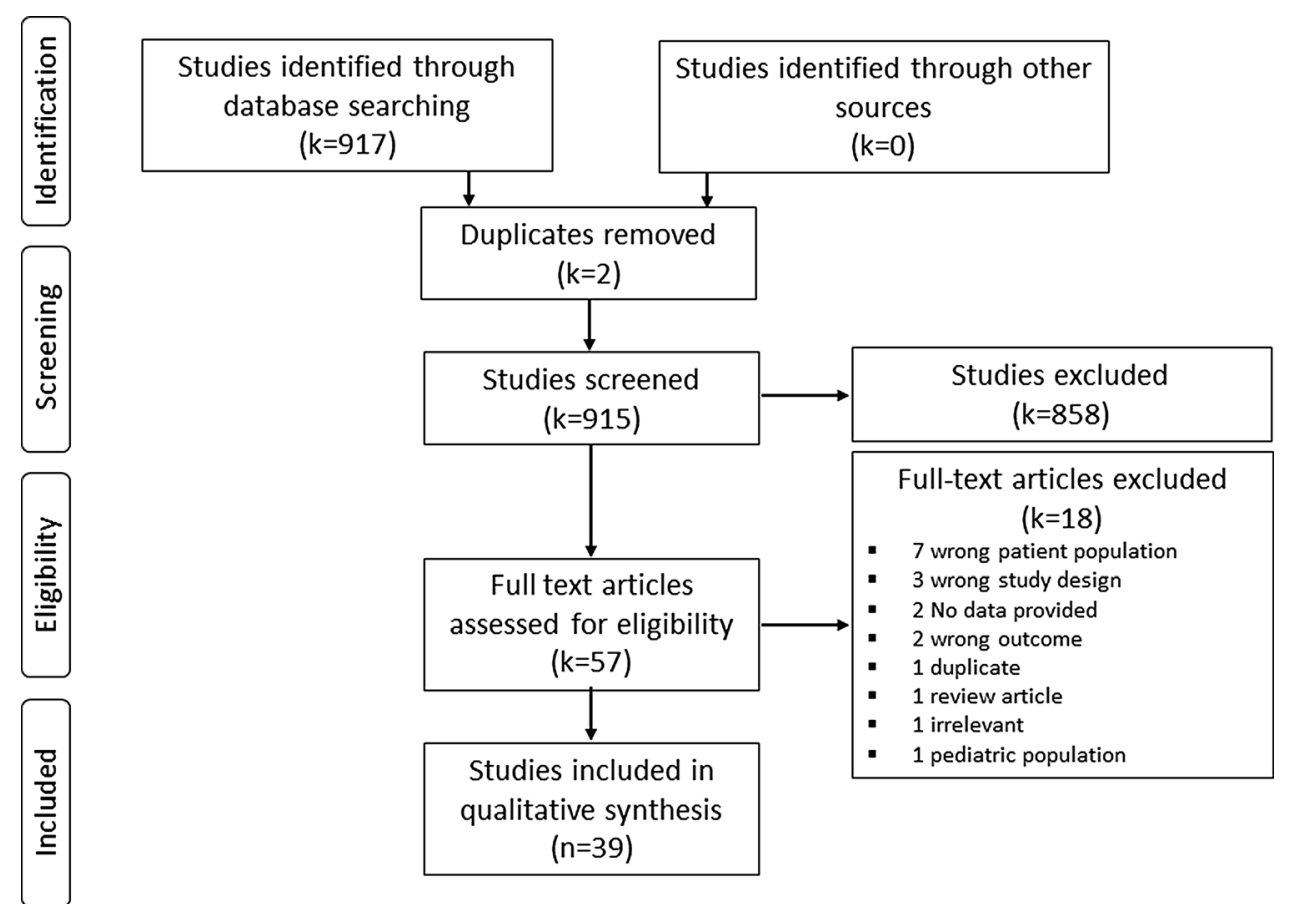

Figure PRISMA flow diagram

to reproduce these findings. It also remains unclear if eosinopenia is simply a marker of severe sepsis and low type 2 immune response, or if they themselves play a role in host defence and injury repair.

Pathomechanistic role of eosinophils in ARDS

The role of eosinophils in lung injury is similarly unclear; eosinophils may appear in the lung either as an effector cell resulting in tissue destruction or be present simply as a response to lung tissue injury and repair. ${ }^{62}$ Studies that have evaluated eosinophil degranulation products (ECP, a marker of eosinophil activity), have shown a consistent association between higher ECP levels and ARDS severity. Nakos et al. ${ }^{52}$ and Haslam et al. ${ }^{63}$ described elevated BAL eosinophils during the late phase of ARDS (eosinophil count $9(4.2) \times 1000 / \mathrm{mL})$, similar to patients with idiopathic pulmonary fibrosis, suggesting a possible link between eosinophils and the development of fibrosis in late-phase ARDS. Increased ECP levels also correlated with ARDS severity. This is in contrast to the single study on peripheral eosinophil activity in sepsis, where high activity was associated with improved survival. ${ }^{49}$ Therefore, eosinophil activation may be part of the inflammatory process in the lung in ARDS. The mechanism of ongoing degranulation needs to be further evaluated as this may be an opportunity for targeted therapy in ARDS, given the lack of consistent benefit with systemic steroids in this condition.

Although the studies describing these associations enrolled heterogeneous groups of patients with ARDS, including those with pulmonary and extrapulmonary ARDS, both direct and indirect inciting factors can lead to activation of common pathways and inflammatory cascades that promote lung injury. ${ }^{64}$ The role of neutrophil activation and pro-inflammatory cytokines (IL6 , IL-1 $\beta, \mathrm{TNF} \alpha$ ) have been well described in the literature. Nevertheless, our understanding of pathways leading to ARDS continues to evolve, and the lack of effective pharmacotherapy highlights the limitations in existing knowledge. Further research into the theragnostic value of eosinophils in ARDS is of interest, particularly because of uncertainties surrounding the mechanism and role for steroids and targeted immunomodulation in ARDS caused by the coronavirus disease (COVID-19) pandemic, given that eosinopenia was observed in more than half of those patients on hospital admission. ${ }^{65,66}$ In a small case series, Liu et al. showed an improved eosinophils count on discharge with the use of the Lopinavir-combined regimen in patients with COVID-19. ${ }^{67}$ The data are limited regarding the role of eosinophils in COVID-19, but they may serve as a prognostic marker for disease severity. ${ }^{68}$

Finally, it is important to highlight that the presence of certain cell types does not necessarily portend a poor 


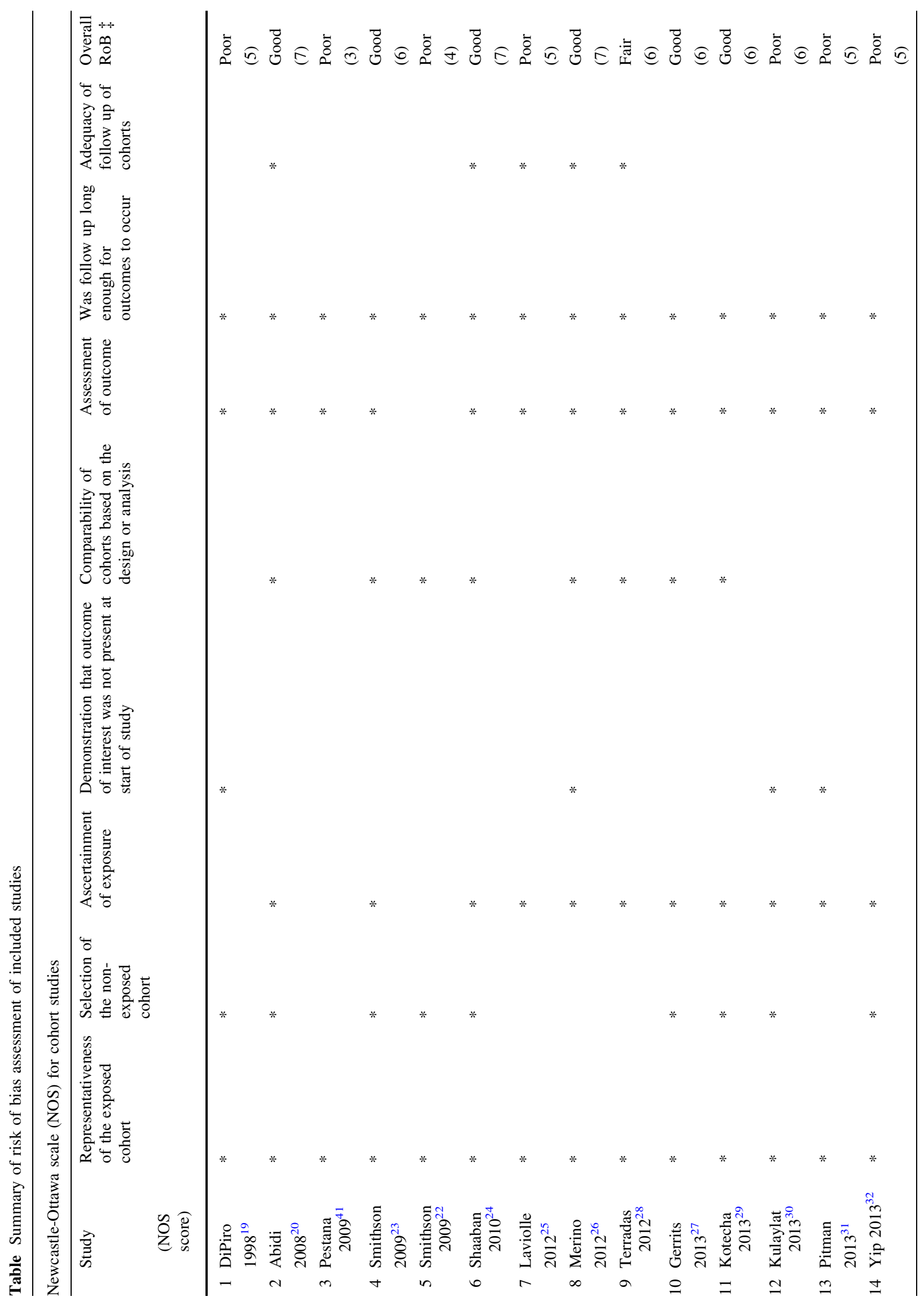




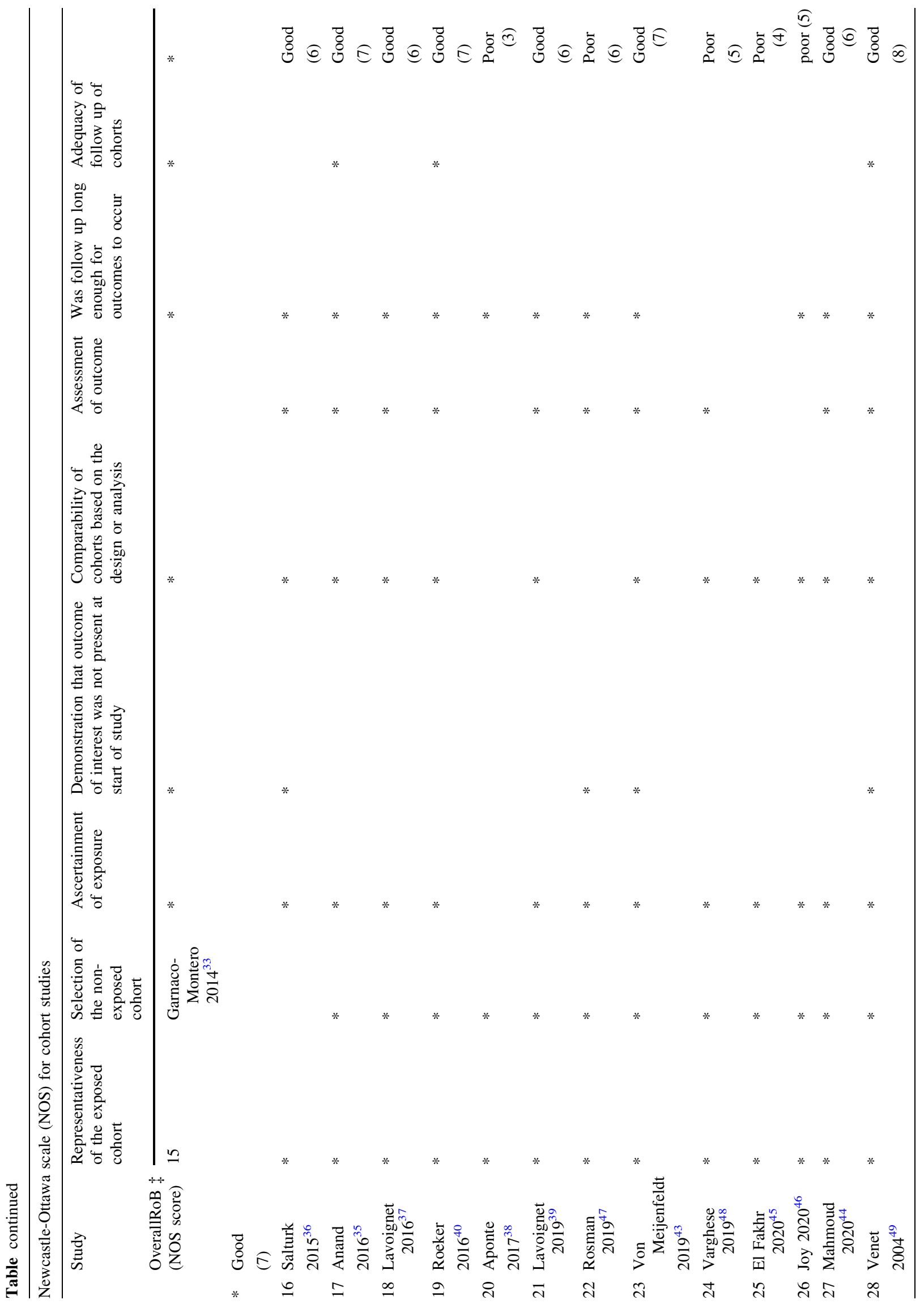




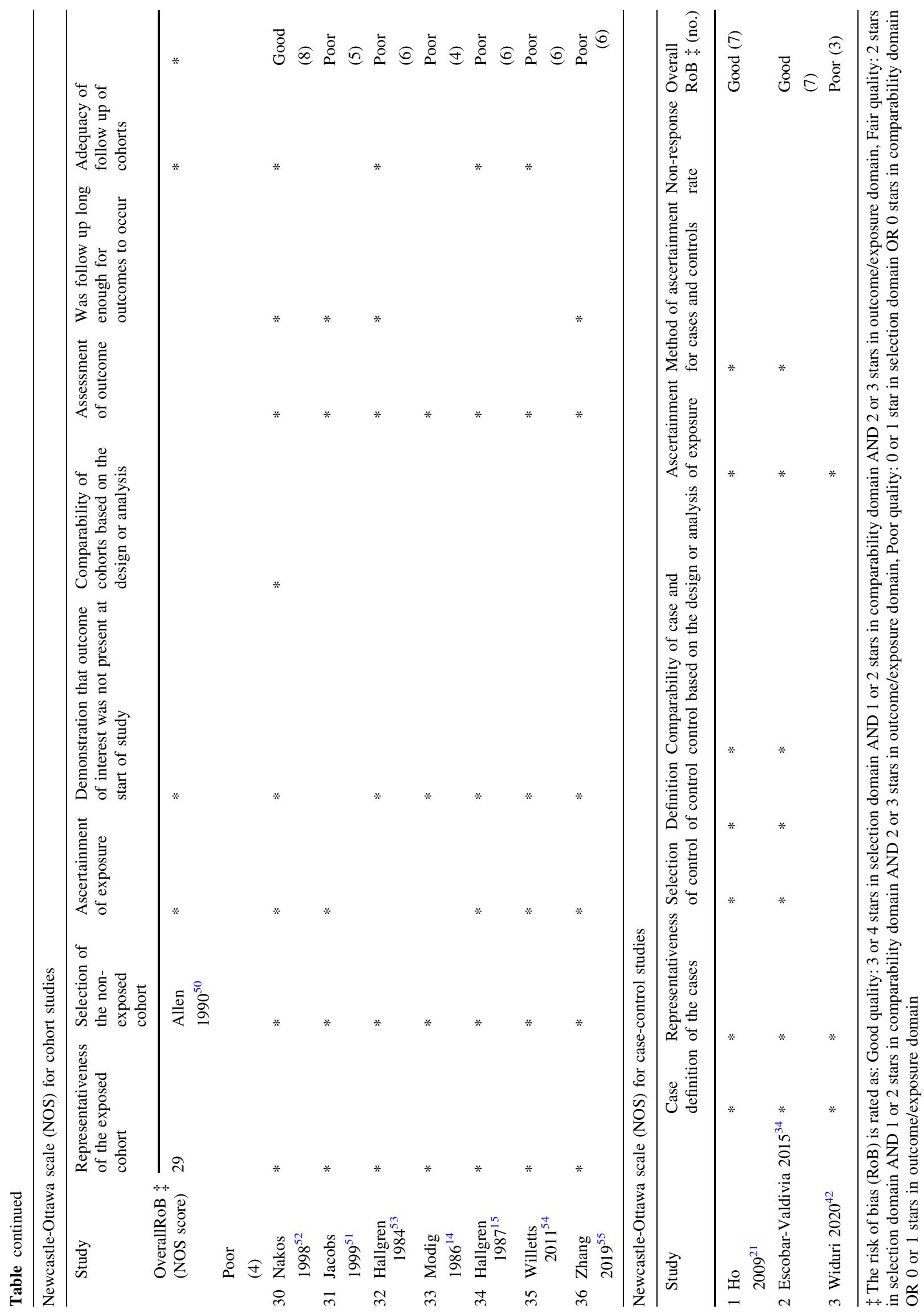


prognosis, as evident from tracheal aspirates of intubated severe asthmatic patients. Ordonez et al. described a higher neutrophil count in the post-extubation tracheal aspirates compared with the counts post-intubation. ${ }^{69}$ While it was expected that the number and activity of neutrophils would be greater when patients were admitted and intubated than when they were well enough to be extubated, the converse was observed. To explain this phenomenon, an ex-vivo sputum analysis was performed revealing impairment of protease-dependent mucus degradation by plasma proteins during acute asthma exacerbation, and that neutrophil recruitment and release of proteases facilitated the mucus clearance in the airway and contributed to clinical improvement. $^{70}$

The strengths of this review include the comprehensive literature search, and independent duplicate judgement about the studies eligible for inclusion, data abstraction, and risk of bias assessment. There are limitations to this review. All studies were observational in nature; inferences on cause-and-effect relationships between eosinopenia and sepsis as well as eosinophils in ARDS are hypothesis generating. Longitudinal studies are needed to better characterize these relationships. In addition, the studies were clinically heterogeneous, which did not allow for pooling of results.

\section{Conclusion}

Eosinophils have a role in predicting survival and severity of sepsis, and low levels of peripheral eosinophil activity are associated with a trend towards poor survival in sepsis. Nevertheless, it remains unclear if eosinophils are simply a marker of disease severity and a reflection of low type 2 immune response, or if they contribute to cellular repair. In contrast, eosinophils may have a mechanistic role in the development and progression of ARDS. Markers of eosinophil activation correlate with the severity of ARDS and may play a role in lung tissue injury and fibrosis. Further understanding of the mechanistic pathways by which eosinophils are depleted in sepsis and by which eosinophil activity is increased in ARDS is needed. Identifying the appropriate endotypes and clinical phenotypes of these patients may allow for appropriate tailoring of available and future therapies.

\section{Future directions}

This review highlights the knowledge gaps, controversies, and the lack of rigorous studies on eosinophils' role in sepsis and ARDS. This article highlights the hypothesis of immune imbalance in sepsis and the potential role of eosinophil infiltration and degranulation in the pathogenesis of sepsis and ARDS. Since the use of corticosteroids is also associated with eosinopenia, it is important to identify, particularly in the context of the current coronavirus disease pandemic-related acute lung injury, if the association with outcomes are independent of concomitant corticosteroid use. Future studies on the causal relationships between eosinopenia, low type 2 immune response, and poor outcomes in sepsis as well as increased eosinophil activity and ARDS severity are needed. Understanding these mechanisms may be the first step in further tailoring the management of patients with sepsis and ARDS.

Author contributions Zainab Al Duhailib contributed to screening titles and abstracts, full-text screening, data abstraction and integrity, risk of bias assessment, preparing the first draft of the manuscript, graphs, tables, and editing the final draft of the manuscript. Malik Farooqi contributed to risk of bias assessment, drafting and editing first and subsequent drafts of the manuscript and tables. Joshua Piticaru contributed to title and abstracts screening, full-text screening, and data abstraction. Waleed Alhazzani contributed critical review of data, review methodology, and manuscript editing. Parameswaran Nair contributed to conception of the project, critical review of data, and manuscript editing

Acknowledgements We would like to acknowledge Kaitryn Campell for her assistance in conducting the literature search.

Guarantor statement Zainab Al Duhailib and Parameswaran Nair provide an overall guarantee to the integrity of this manuscript.

Disclosures None.

Funding statement Dr. Nair is supported by the Frederick E. Hargreave Teva Innovation Chair in Airway Diseases.

Editorial responsibility This submission was handled by Dr. Sangeeta Mehta, Associate Editor, Canadian Journal of Anesthesia.

\section{References}

1. Singer $M$, Deutschman CS, Seymour CW, et al. The Third International Consensus Definitions for Sepsis and Septic Shock (Sepsis-3). JAMA 2016; 315: 801-10.

2. Mikkelsen ME, Shah CV, Meyer NJ, et al. The epidemiology of acute respiratory distress syndrome in patients presenting to the emergency department with severe sepsis. Shock 2013; 40: 375-81.

3. Rhodes A, Evans LE, Alhazzani W, et al. Surviving Sepsis Campaign: International Guidelines for Management of Sepsis and Septic Shock: 2016. Intensive Care Med 2017; 43: 304-77.

4. Sprung CL, Annane D, Keh D, et al. Hydrocortisone therapy for patients with septic shock. N Engl J Med 2008; 358: 111-24.

5. Annane D, Pastores SM, Rochwerg B, et al. Guidelines for the Diagnosis and Management of Critical Illness-Related Corticosteroid Insufficiency (CIRCI) in Critically Ill Patients (Part I): Society of Critical Care Medicine (SCCM) and European 
Society of Intensive Care Medicine (ESICM) 2017. Crit Care Med 2017; 45: 2078-88.

6. Jayaram L, Pizzichini MM, Cook RJ, et al. Determining asthma treatment by monitoring sputum cell counts: effect on exacerbations. Eur Respir J 2006; 27: 483-94.

7. Brightling CE, Ward $R$, Wardlaw AJ, Pavord ID. Airway inflammation, airway responsiveness and cough before and after inhaled budesonide in patients with eosinophilic bronchitis. Eur Respir J 2000; 15: 682-6.

8. Pizzichini E, Pizzichini MM, Gibson P, et al. Sputum eosinophilia predicts benefit from prednisone in smokers with chronic obstructive bronchitis. Am J Respir Crit Care Med 1998; 158(5 Pt 1): 1511-7.

9. Delano MJ, Ward PA. Sepsis-induced immune dysfunction: can immune therapies reduce mortality? J Clin Invest 2016; 126: 23-31.

10. Wong JJ, Leong JY, Lee JH, Albani S, Yeo JG. Insights into the immuno-pathogenesis of acute respiratory distress syndrome. Ann Transl Med 2019; DOI: https://doi.org/10.21037/atm.2019. 09.28.

11. Spellberg B, Edwards JE Jr. Type 1/type 2 immunity in infectious diseases. Clin Infect Dis 2001; 32: 76-102.

12. Eberl G. Immunity by equilibrium. Nat Rev Immunol 2016; 16 : 524-32.

13. Ramirez GA, Yacoub MR, Ripa M, et al. Eosinophils from physiology to disease: a comprehensive review. Biomed Res Int 2018; DOI: https://doi.org/10.1155/2018/9095275.

14. Modig J, Samuelsson T, Hallgren $R$. The predictive and discriminative value of biologically active products of eosinophils, neutrophils and complement in bronchoalveolar lavage and blood in patients with adult respiratory distress syndrome. Resuscitation 1986; 14: 121-34.

15. Hallgren $R$, Samuelsson $T$, Venge $P$, Modig $J$. Eosinophil activation in the lung is related to lung damage in adult respiratory distress syndrome. Am Rev Respir Dis 1987; 135: 639-42.

16. McGowan J, Sampson M, Salzwedel DM, Cogo E, Foerster V, Lefebvre $C$. PRESS peer review of electronic search strategies: 2015 guideline statement. J Clin Epidemiol 2016; 75: 40-6.

17. Al Duhailib J, Farooqi M, Piticaru J, Alhazzani W, Nair P. Registry of Systematic Reviews/Meta-Analyses Details. The role of eosinophils in sepsis and acute respiratory distress syndrome: a scoping review. Available from URL: https://www. researchregistry.com/browse-the-

registry\#registryofsystematicreviewsmeta-analyses/ registryofsystematicreviewsmeta-analysesdetails/ 5f4f5d1deb323a00150f7c06/ (accessed December 2020).

18. Wells GA, O'Connell D, Peterson J, Welch V, Losos M, Tugwell $P$. The Newcastle-Ottawa Scale (NOS) for assessing the quality of nonrandomised studies in meta-analyses. Available from URL: http://www.ohri.ca/programs/clinical_epidemiology/oxford.asp (accessed December 2020).

19. DiPiro JT, Howdieshell TR, Hamilton RG, Mansberger AR Jr. Immunoglobulin $\mathrm{E}$ and eosinophil counts are increased after sepsis in trauma patients. Crit Care Med 1998; 26: 465-9.

20. Abidi K, Khoudri I, Belayachi J, et al. Eosinopenia is a reliable marker of sepsis on admission to medical intensive care units. Crit Care 2008; DOI: https://doi.org/10.1186/cc6883.

21. Ho KM, Towler SC. A comparison of eosinopenia and C-reactive protein as a marker of bloodstream infections in critically ill patients: a case control study. Anaesth Intensive Care 2009; 37: 450-6.

22. Smithson A, Perello R, Sobrino J, Nicolas JM. Eosinophil count probably not useful at all in postsurgical septic shock patients. J Trauma 2009; DOI: https://doi.org/10.1097/TA. 0b013e3181ad5263.
23. Smithson A, Perello R, Nicolas JM. Is eosinopenia a reliable marker of sepsis? Crit Care 2009; DOI: https://doi.org/10.1186/ cc7877.

24. Shaaban H, Daniel S, Sison R, Slim J, Perez G. Eosinopenia: is it a good marker of sepsis in comparison to procalcitonin and C-reactive protein levels for patients admitted to a critical care unit in an urban hospital? J Crit Care 2010; 25: 570-5.

25. Laviolle B, Annane D, Fougerou C, Bellissant E. Gluco- and mineralocorticoid biological effects of a 7-day treatment with low doses of hydrocortisone and fludrocortisone in septic shock. Intensive Care Med 2012; 38: 1306-14.

26. Merino CA, Martinez FT, Cardemil F, Rodriguez JR. Absolute eosinophils count as a marker of mortality in patients with severe sepsis and septic shock in an intensive care unit. J Crit Care 2012; 27: 394-9.

27. Gerrits JH, McLaughlin PM, Nienhuis BN, Smit JW, Loef B. Polymorphic mononuclear neutrophils CD64 index for diagnosis of sepsis in postoperative surgical patients and critically ill patients. Clin Chem Lab Med 2013; 51: 897-905.

28. Terradas $R$, Grau $S$, Blanch $J$, et al. Eosinophil count and neutrophil-lymphocyte count ratio as prognostic markers in patients with bacteremia: a retrospective cohort study. PLoS One 2012; DOI: https://doi.org/10.1371/journal.pone.0042860.

29. Kotecha HL, Arora A, Chawlani R, et al. Low eosinophil count predicts in-hospital mortality in cirrhosis with systemic inflammatory response syndrome. Eur J Gastroenterol Hepatol 2013; 25: 676-82.

30. Kulaylat AS, Buonomo EL, Scully $K W$, et al. Development and validation of a prediction model for mortality and adverse outcomes among patients with peripheral eosinopenia on admission for clostridium difficile infection. JAMA Surg 2018; 153: 1127-33.

31. Pitman MC, Anstey NM, Davis JS. Eosinophils in severe sepsis in Northern Australia: do the usual rules apply in the tropics? Crit Care Med 2013; 41: e286-8.

32. Yip B, Ho KM. Eosinopenia as a predictor of unexpected readmission and mortality after intensive care unit discharge. Anaesth Intensive Care 2013; 41: 231-41.

33. Garnacho-Montero J, Huici-Moreno MJ, Gutierrez-Pizarraya A, et al. Prognostic and diagnostic value of eosinopenia, C-reactive protein, procalcitonin, and circulating cell-free DNA in critically ill patients admitted with suspicion of sepsis. Crit Care 2014; DOI: https://doi.org/10.1186/cc13908.

34. Escobar-Valdivia EJ, Gonzalez-Aguirre JE, Carrillo-Cisneros ER, Guerra-Leza KC, Mercado-Longoria R. Eosinophil count at intensive care unit admission was not predictor of hospital mortality: results of a case control study. J Intensive Care 2015; DOI: https://doi.org/10.1186/s40560-015-0093-4.

35. Anand D, Ray $S$, Bhargava $S$, et al. Exploration of eosinopenia as a diagnostic parameter to differentiate sepsis from systemic inflammatory response syndrome: results from an observational study. Indian J Crit Care Med 2016; 20: 285-90.

36. Salturk $C$, Karakurt Z, Adiguzel N, et al. Does eosinophilic COPD exacerbation have a better patient outcome than noneosinophilic in the intensive care unit? Int J Chron Obstruct Pulmon Dis 2015; 10: 1837-46.

37. Lavoignet CE, Le Borgne P, Slimani $H$, et al. Relevance of eosinopenia as marker of sepsis in the emergency department (French). Re Med Interne 2016; 37: 730-4.

38. Aponte J, Carrizosa J, Sanchez A, et al. Procalcitonin and eosinopenia as potential biomarkers of infection in critically ill patients with systemic lupus erythematosus. Lupus Sci Med 2017; 4: A94-5 (abstract).

39. Lavoignet CE, Le Borgne P, Chabrier S, et al. White blood cell count and eosinopenia as valuable tools for the diagnosis of 
bacterial infections in the ED. Eur J Clin Microbiol Infect Dis 2019; 38: 1523-32.

40. Roeker LE, Horkan CM, Gibbons FK, Christopher KB. Eosinopenia in ICU survivors and post-hospital outcomes. Intensive Care Med Exp 2016; DOI: https://doi.org/10.1186/ s40635-016-0099-9.

41. Pestana D, Martinez-Casanova E, Buno A, Madero R, Criado A; REASEP Sepsis Study Group. Baseline cortisol levels, total proteins, and eosinophil count as predictors of hemodynamic response to steroid treatment in septic shock. J Trauma 2009; 66: 1060-4.

42. Widuri $U$, Hadi $U$, Arfijanto $M V$. Eosinophil level with severity of sepsis based on sequential organ failure assessment score. Int $\mathbf{J}$ Pharmaceutical Res 2020; 12: 1403-8.

43. von Meijenfeldt GC, Chary S, van der Laan MJ, Zeebregts CJ, Christopher $K B$. Eosinopenia and post-hospital outcomes in critically ill non-cardiac vascular surgery patients. Nutr Metab Cardiovasc Dis 2019; 29: 847-55.

44. Mahmoud O, Chen B, Chakraborti A, Salonia J. Eosinopenia as a predictor of mortality in the intensive care unit: a retrospective analysis. Am J Respir Crit Care Med 2020; 201: A6321 (abstract)

45. El Fakhr K, Rabiou HH, Marhfour, Charra B. Eosinopenia in sepsis. Ann Intensive Care 2020; 10(Suppl 1): P-059 (abstract).

46. Joy AP, Murali AB, Joshi MA, Parambil JC. Absolute eosinophil count as a diagnostic and prognostic marker compared to Creactive protein and procalcitonin in patients with sepsis. Clin Epidemiol Global Health 2020; DOI: https://doi.org/10.1016/j. cegh.2019.12.017.

47. Rosman J, Hainguerlot S, Cordonnier A, et al. Severe eosinopenia as a predictive factor of ICU admission in infected patients admitted in an emergency department. Ann Intensive Care 2019; 9(Suppl 1): P-30 (abstract).

48. Varghese JI, Devadas K, Cyriac R, Vinayakumar N, Hareendran A, Iqbal A. Low eosinophil count, a predictor of 28 day mortality in a cohort of cirrhosis patients with sepsis. E-Poster Presentations (Oral) I APDW 2019. J Gastroenterol Hepatol 2019; https://doi.org/10.1111/jgh.14879.

49. Venet $F$, Lepape A, Debard AL, Bienvenu J, Bohe J, Monneret $G$. The Th2 response as monitored by CRTH 2 or CCR 3 expression is severely decreased during septic shock. Clin Immunol 2004; 113: 278-84.

50. Allen JN, Davis WB, Pacht ER. Diagnostic significance of increased bronchoalveolar lavage fluid eosinophils. Am Rev Respir Dis 1990; 142: 642-7.

51. Jacobs JA, De Brauwer EI, Ramsay G, et al. Detection of noninfectious conditions mimicking pneumonia in the intensive care setting: usefulness of bronchoalveolar fluid cytology. Respir Med 1999; 93: 571-8.

52. Nakos G, Kitsiouli EI, Tsangaris I, Lekka ME. Bronchoalveolar lavage fluid characteristics of early intermediate and late phases of ARDS. Alterations in leukocytes, proteins, PAF and surfactant components. Intensive Care Med 1998; 24: 296-303.

53. Hallgren R, Borg T, Venge P, Modig J. Signs of neutrophil and eosinophil activation in adult respiratory distress syndrome. Crit Care Med 1984; 12: 14-8.

54. Willetts L, Parker K, Wesselius LJ, et al. Immunodetection of occult eosinophils in lung tissue biopsies may help predict survival in acute lung injury. Respir Res 2011; DOI: https://doi. org/10.1186/1465-9921-12-116.
55. Zhang D, Wang $Y$. Eosinophils count as a prognostic marker in acute respiratory distress syndrome. Respirology 2019; DOI: https://doi.org/10.1111/resp.13700_379.

56. Bone RC, Balk RA, Cerra FB, et al. Definitions for sepsis and organ failure and guidelines for the use of innovative therapies in sepsis. The ACCP/SCCM Consensus Conference Committee. American College of Chest Physicians/Society of Critical Care Medicine. Chest 1992; 101: 1644-55.

57. Linch SN, Danielson ET, Kelly AM, Tamakawa RA, Lee JJ, Gold $J A$. Interleukin 5 is protective during sepsis in an eosinophilindependent manner. Am J Respir Crit Care Med 2012; 186: 246-54.

58. Percopo CM, Dyer KD, Ochkur SI, et al. Activated mouse eosinophils protect against lethal respiratory virus infection. Blood 2014; 123: 743-52.

59. Yousefi S, Gold JA, Andina N, et al. Catapult-like release of mitochondrial DNA by eosinophils contributes to antibacterial defense. Nat Med 2008; 14: 949-53.

60. Krishack PA, Louviere TJ, Decker TS, et al. Protection against staphylococcus aureus bacteremia-induced mortality depends on ILC2s and eosinophils. JCI Insight 2019; DOI: https://doi.org/10. 1172/jci.insight.124168.

61. Bass DA, Gonwa TA, Szejda P, Cousart MS, DeChatelet LR, McCall CE. Eosinopenia of acute infection: production of eosinopenia by chemotactic factors of acute inflammation. J Clin Invest 1980; 65: 1265-71.

62. Lee JJ, Jacobsen EA, McGarry MP, Schleimer RP, Lee NA. Eosinophils in health and disease: the LIAR hypothesis. Clin Exp Allergy 2010; 40: 563-75.

63. Haslam PL, Turton CW, Lukoszek A, et al. Bronchoalveolar lavage fluid cell counts in cryptogenic fibrosing alveolitis and their relation to therapy. Thorax $1980 ; 35: 328-39$.

64. Thompson BT, Chambers RC, Liu KD. Acute respiratory distress syndrome. N Engl J Med 2017; 377: 562-72.

65. Zhao $M$. Cytokine storm and immunomodulatory therapy in COVID-19: role of chloroquine and anti-IL-6 monoclonal antibodies. Int J Antimicrob Agents 2020; DOI: https://doi.org/ 10.1016/j.ijantimicag.2020.105982.

66. Zhang JJ, Dong X, Cao Y, et al. Clinical characteristics of 140 patients infected with SARS-CoV-2 in Wuhan. China. Allergy 2020; DOI: https://doi.org/10.1111/all.14238.

67. Liu F, Хи A, Zhang $Y$, et al. Patients of COVID-19 may benefit from sustained lopinavir-combined regimen and the increase of eosinophil may predict the outcome of COVID-19 progression. Int J Infect Dis 2020; 95: 183-91.

68. Lindsley $A W$, Schwartz JT, Rothenberg ME. Eosinophil responses during COVID-19 infections and coronavirus vaccination. J Allergy Clin Immunol 2020; DOI: https://doi.org/10.1016/j. jaci.2020.04.021.

69. Ordonez CL, Shaughnessy TE, Matthay MA, Fahy JV. Increased neutrophil numbers and IL-8 levels in airway secretions in acute severe asthma: clinical and biologic significance. Am J Respir Crit Care Med 2000; 161(4 Pt 1): 1185-90.

70. Innes $A L$, Carrington SD, Thornton DJ, et al. Ex vivo sputum analysis reveals impairment of protease-dependent mucus degradation by plasma proteins in acute asthma. Am J Respir Crit Care Med 2009; 180: 203-10.

Publisher's Note Springer Nature remains neutral with regard to jurisdictional claims in published maps and institutional affiliations. 